\title{
BMJ Open Aetiology, course and treatment of acute tubulointerstitial nephritis in paediatric patients: a cross-sectional web- based survey
}

\begin{abstract}
Sarah Wente-Schulz, ${ }^{1}$ Marina Aksenova, ${ }^{2}$ Atif Awan, ${ }^{3}$ Cahyani Gita Ambarsari, ${ }^{4}$ Francesca Becherucci, ${ }^{5}$ Francesco Emma, ${ }^{6}$ Marc Fila (D) , Telma Francisco, ${ }^{8}$ Ibrahim Gokce, ${ }^{9}$ Bora Gülhan, ${ }^{10}$ Matthias Hansen, ${ }^{11}$ Timo Jahnukainen, ${ }^{12}$ Mahmoud Kallash, ${ }^{13}$ Konstantinos Kamperis, ${ }^{14}$ Sherene Mason, ${ }^{15}$ Antonio Mastrangelo, ${ }^{16}$ Francesca Mencarelli, ${ }^{17}$ Bogna Niwinska-Faryna, ${ }^{18}$ Michael Riordan, ${ }^{3}$ Rina R Rus, ${ }^{19}$ Seha Saygili, ${ }^{20}$ Erkin Serdaroglu, ${ }^{21}$ Sevgin Taner, ${ }^{22}$ Rezan Topaloglu, ${ }^{10}$ Enrico Vidal, ${ }^{23}$ Robert Woroniecki, ${ }^{24}$ Sibel Yel, ${ }^{25}$ Jakub Zieg, ${ }^{26}$ Lars Pape (1) ,27 The international TIN study group
\end{abstract}

To cite: Wente-Schulz S, Aksenova M, Awan A, et al. Aetiology, course and treatment of acute tubulointerstitial nephritis in paediatric patients: a cross-sectional web-based survey. BMJ Open 2021;11:e047059. doi:10.1136/ bmjopen-2020-047059

- Prepublication history and additional supplemental material for this paper are available online. To view these files, please visit the journal online (http://dx.doi.org/10.1136/ bmjopen-2020-047059)

Received 19 November 2020 Accepted 13 May 2021
Check for updates

(C) Author(s) (or their employer(s)) 2021. Re-use permitted under CC BY-NC. No commercial re-use. See rights and permissions. Published by BMJ.

For numbered affiliations see end of article.

Correspondence to

Professor Lars Pape; lars.pape@uk-essen.de

\section{ABSTRACT}

Background Acute tubulointerstitial nephritis (TIN) is a significant cause of acute renal failure in paediatric and adult patients. There are no large paediatric series focusing on the aetiology, treatment and courses of acute TIN.

Patients, design and setting We collected retrospective clinical data from paediatric patients with acute biopsyproven TIN by means of an online survey. Members of four professional societies were invited to participate.

Results Thirty-nine physicians from 18 countries responded. 171 patients with acute TIN were included (54\% female, median age 12 years). The most frequent causes were tubulointerstitial nephritis and uveitis syndrome in 31\% and drug-induced TIN in 30\% (the majority of these caused by non-steroidal anti-inflammatory drugs). In $28 \%$ of patients, no initiating noxae were identified (idiopathic TIN). Median estimated glomerular filtration rate (eGFR) rose significantly from 31 at time of renal biopsy to $86 \mathrm{~mL}$ $\mathrm{min} / 1.73 \mathrm{~m}^{2} 3-6$ months later $(\mathrm{p}<0.001)$. After $3-6$ months, eGFR normalised in $41 \%$ of patients (eGFR $\geq 90 \mathrm{~mL}$ / $\min / 1.73 \mathrm{~m}^{2}$ ), with only $3 \%$ having severe or end-stage impairment of renal function $\left(<30 \mathrm{~mL} / \mathrm{min} / 1.73 \mathrm{~m}^{2}\right) .80 \%$ of patients received corticosteroid therapy. Median eGFR after 3-6 months did not differ between steroid-treated and steroid-untreated patients. Other immunosuppressants were used in $18 \%(n=31)$ of patients, 21 of whom received mycophenolate mofetil.

Conclusions Despite different aetiologies, acute paediatric TIN had a favourable outcome overall with $88 \%$ of patients showing no or mild impairment of eGFR after 3-6 months. Prospective randomised controlled trials are needed to evaluate the efficacy of glucocorticoid treatment in paediatric patients with acute TIN.

\section{INTRODUCTION}

Acute tubulointerstitial nephritis (TIN) is a significant cause of acute renal failure in

\section{Strengths and limitations of this study}

Largest study on children with tubulointerstitial nephritis.

- Patients from all parts of the word included as a joint project of the most important societies for paediatric nephrology.

- Retrospective data collected in a survey.

Short follow-up period.

Detailed results of renal biopsy were not available.

paediatric and adult patients. TIN accounts for approximately $2 \%-3 \%$ of native renal biopsies. ${ }^{1-3}$ In biopsies to evaluate acute renal failure of unknown origin, TIN represents about $13 \%$ of cases in adult patients. ${ }^{23}$ Reliable data on the incidence and prevalence of paediatric TIN are lacking.

Renal histopathology in TIN is characterised by interstitial cellular infiltrates and oedema, but vessels and glomeruli are typically spared. ${ }^{4}$ The inflammatory process may eventually lead to interstitial fibrosis and chronic kidney disease. ${ }^{5}$

Numerous causes of TIN are known, with drugs, especially non-steroidal antiinflammatory drugs (NSAIDs), being the trigger in $60 \%-70 \%$ of cases $^{6}$; however, the identity of the causative agent in cases of TIN is usually speculative. Other cases of TIN are related to infections or systemic diseases. In some cases, renal disease can be accompanied by uveal inflammation (tubulointerstitial nephritis with uveitis (TINU)). ${ }^{78}$ Other TIN cases are presumed to be idiopathic. ${ }^{4}$ Despite 
the different aetiologies of TIN, a common immunemediated pathogenic mechanism is assumed. Antigenmediated cellular immune responses seem to play a key role in the pathogenesis of TIN. ${ }^{39}$ It is also important to note that this is a very heterogeneous group of patients. While histopathology is similar, TIN due to sarcoidosis is probably biologically distinct entity from that due to antibiotics, recreational drugs, NSAIDS and infectious agents. Clinical symptoms of TIN are often non-specific and therefore may lead to delayed diagnosis and treatment. $^{410}$

Corticosteroids are well established in the treatment of severe TIN, although prospective randomised controlled clinical trials assessing the indications and efficacy of corticosteroid treatment are not available. In adult patients, retrospective data indicated beneficial effects of corticosteroids on renal function recovery in drug-induced TIN. ${ }^{11-14}$ However, results of other retrospective studies did not support the routine administration of corticosteroid therapy. ${ }^{15}$ Results from a small prospective paediatric study showed an accelerated renal recovery with corticosteroid treatment. ${ }^{16}$ There is very limited experience of the use of other immunosuppressive agents (eg, mycophenolate mofetil (MMF)) in patients with TIN. Moreover, there is no consensus on a standard therapeutic regimen (eg, intravenous vs oral administration, dosage and duration of therapy) in either children or adults.

In this study, we assessed the aetiology, therapy and clinical course of TIN in a large paediatric cohort with manifestation of acute TIN between 2007 and 2018. Data were collected retrospectively via a survey circulated to members of the German Society of Pediatric Nephrology (GPN), European Society of Pediatric Nephrology (ESPN), European Network of Rare Kidney Diseases (ERKnet) and Pediatric Nephrology Research Consortium (PNRC) based in the USA.

\section{PATIENTS AND METHODS}

Members of GPN, ESPN, ERKNet and PNRC were invited to participate in the online survey. An email invitation with a summary of the project and a link to an online questionnaire service provider (https://www.google. $\mathrm{de} / \mathrm{intl} / \mathrm{de} /$ forms/about/) was sent to all mailing list contacts of GPN, ESPN, ERKNet and PNRC. The survey was launched in April 2018 and was closed in June 2019.

The data collection was retrospective and fully anonymised. Only patients with biopsy-proven TIN were included in the study. Further inclusion criteria were age between 0 and 18 years, and presentation of disease was between 2007 and 2018.

The questionnaire comprised 57 items. Answers were given as multiple choice or short free texts assessing the incidence, aetiology and course of acute TIN in children. 'Yes', 'no' and 'not assessed' were given as answer options for disease symptoms, urinary findings and biopsy results. Free-text answers were required for precise causative factors for TIN (eg, drug name, pathogen, underlying systemic disease). The questionnaire is provided in the online supplemental material.

Creatinine-based 'Bedside Schwartz' formula (estimated glomerular filtration rate $(\mathrm{eGFR})=0.413 \times$ (height $/$ Scr)) was used for eGFR. ${ }^{17}$

The responses were automatically collected in a database provided by the survey administration app. All statistical data analyses were performed in GraphPad Prism V.8 (https://www.graphpad.com). Continuous variables were expressed as median, and range as no normal distribution was assumed. Three different non-parametric tests were used for analysis of non-normally distributed variables: Mann-Whitney U test and Kruskal-Wallis test were used, respectively, to compare medians of two groups and three or more groups of variables not normally distributed; one sample Wilcoxon test was conducted for comparison of paired data. Statistical significance of dichotomous variables was measured by using the $\chi^{2}$ test. $\mathrm{P}<0.05$ was considered statistically significant.

\section{ETHICS APPROVAL}

The study was approved by the council of the ESPN, GPN, ERKNet and PNRC. Requests for authorisation by the ethics committees of the other centres were not considered necessary because this was a survey that simply collected the experience and practices of the physicians, and it did not involve approaching patients directly or seeking any patient-specific data.

\section{Patient and public involvement}

Patients and public were not involved in the design and conduct of this study.

\section{RESULTS}

Thirty-nine clinicians from 18 countries participated in the survey. One hundred and seventy-one patient cases were included in the final analysis. Patients originated from Northern Europe $(n=41)$, Southern Europe $(n=38)$, Western Europe $(n=25)$, Eastern Europe $(n=8)$, Western Asia $(n=31)$, Southern Asia $(n=1)$, Southeastern Asia $(\mathrm{n}=5)$ and Northern America $(\mathrm{n}=22)$.

Gender distribution was equal with 93 (54\%) females and 78 males $(46 \%)$. The median age (range) was 13 (1-17) years at diagnosis with the following age distribution: $1-5$ years: $9 \%$ (16/171); 6-12 years: $38 \%$ (64/171); 13-18 years: $53 \%(91 / 171)$ (see figure 1 ).

\section{Atiology}

About one-third of TIN cases was drug related or induced by a toxic agent $(30 \%, 52 / 171)$. TINU syndrome accounts for another third of included cases $(31 \%, 53 / 171)$. Twenty-eight per cent $(48 / 171)$ of cases were presumed to be idiopathic. Systemic diseases $(7 \%, 11 / 171)$ and infections $(4 \%, 7 / 171)$ were rare causes of acute interstitial nephritis (see figure 2). Infectious causes were most 


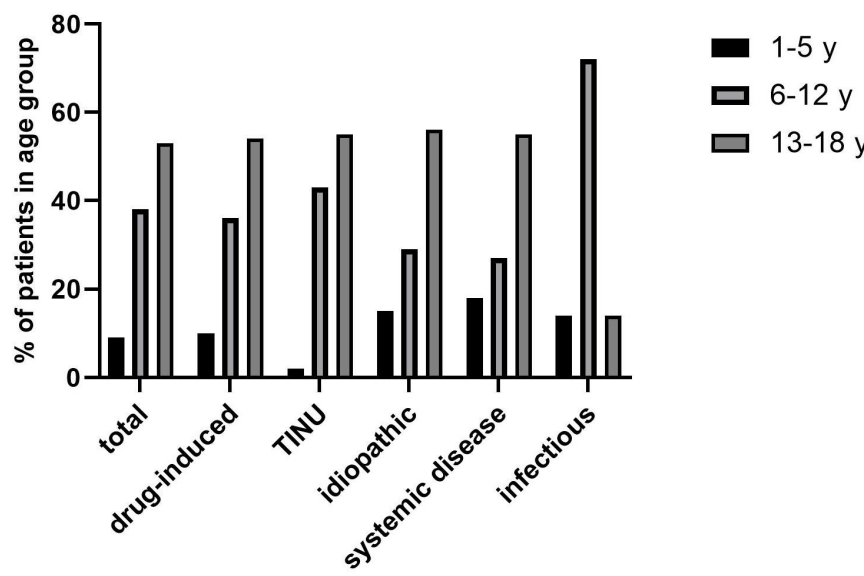

Figure 1 Age distribution of 171 patients with acute tubulointerstitial nephritis. TINU, tubulointerstitial nephritis with uveitis.

prevalent in patients aged 6-12 years. TIN from other causes was predominant in teenage patients (13-18 years) (see figure 1).

\section{Drug-induced TIN}

NSAIDs and antimicrobials were identified as the most common causative drugs and represented $79 \%$ (41/52) of drug-induced TIN cases. NSAIDs alone accounted for $48 \%(25 / 52)$ of drug-induced cases, while $10 \%(5 / 52)$ of patients received a combination of NSAIDs and antibiotics. Twenty-one per cent $(11 / 52)$ of drug-induced cases were based on the administration of antimicrobial therapy (antiviral or antibacterial) without comedication. Other less frequent substances were identified in $21 \%$ $(11 / 52)$ (see table 1$)$.

Median age (13 years, range 1-17) and gender distribution $(24 / 52=46 \%$ male, $28 / 52=54 \%$ female) did not differ from the total group.

\section{TINU syndrome}

TINU syndrome showed a slight predominance in females $(58 \%=31 / 53$ female, $42 \%=22 / 53$ male $)$ without statistical significance. Median age of onset was equal to the total group (13 years) with an age range between 5 and 17 years.

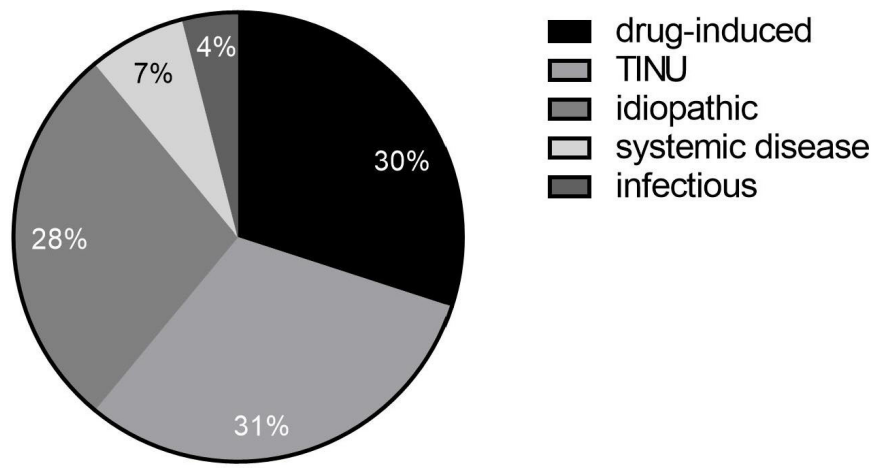

Figure 2 Aetiology of acute tubulointerstitial nephritis in 171 paediatric patients. TINU, tubulointerstitial nephritis with uveitis.
Table 1 Drugs and toxic agents as causes of tubulointerstitial nephritis (TIN) in 52 patients with acute TIN

\begin{tabular}{lrl}
\hline NSAIDs (without comedication) & 25 & $48 \%$ \\
\hline Ibuprofen & 6 & \\
\hline Flurbiprofen & 3 & \\
\hline Morniflumate & 3 & \\
\hline Ketoprofen & 1 & \\
\hline Unspecified & 12 & \\
\hline Antimicrobials & 11 & $21 \%$ \\
\hline Acyclovir & 1 & \\
\hline Amoxicillin \pm clavulanic acid & 3 & \\
\hline Trimethoprim/sulfamethoxazole & 1 & \\
Midecamycin & 1 & \\
\hline Penicillin & 2 & \\
Unspecified & 1 & \\
Combination of antibiotics & 2 & \\
\hline NSAIDs+antimicrobials & 5 & $10 \%$ \\
\hline Others & 11 & $21 \%$ \\
\hline Bee venom & 2 & \\
\hline Herbal medicines & 3 & \\
\hline Mesalazine & 2 & \\
\hline Levetiracetam+oxcarbazepine & 1 & \\
\hline Paracetamol+chlorphenamine maleate & 1 & \\
\hline Hydrochlorothiazide & 1 & \\
\hline Smoking & 1 & \\
\hline
\end{tabular}

NSAIDs, non-steroidal anti-inflammatory drugs.

Idiopathic TIN

In $28 \%(48 / 171)$ of cases no acute TIN trigger could be identified. Median age (range) was 13 years (3-16) with a balanced gender distribution of $50 \%(24 / 48)$ males and $50 \%(24 / 48)$ females.

TIN associated with systemic diseases

Median age (range) of onset was 14 years (1-17). Sixtyfour per cent (7/11) were female and 36\% (4/11) male patients. For a complete list of diagnoses see box 1 .

TIN associated with infections

Median age (range) was 11 years (1-15), and included four male $(57 \%, 4 / 7)$ and three female patients $(43 \%$, $3 / 7$ ). Adenovirus, BK polyoma virus, hepatitis $\mathrm{C}$ virus and rhinovirus were reported in one patient each. Three patients showed symptoms of upper respiratory tract infection without pathogen identification.

Clinical and urinary features

Clinical and urinary features in the patient cohort are summarised in table 2. The most frequent clinical symptom at presentation of disease was fatigue in $70 \%$ $(119 / 171)$ of patients, followed by vomiting or nausea in $49 \%(83 / 169$; no data=2) and fever in $43 \%(73 / 171)$ 
Box 1 List of diagnoses in patients with systemic

diseases as causes of acute tubulointerstitial nephritis

(TIN). Two patients were diagnosed with Sjögren's

syndrome, all other diagnoses were made in one patient

each

Sarcoidosis.

Sjögren's syndrome.

Autoimmune polyendocrinopathy-candidiasis-ectodermal dystrophy

type 1.

Atypic haemolytic syndrome.

Microscopic polyangiitis.

Familial Mediterranean fever.

Metabolic disease (undefined).

Chronic osteomyelitis.

Juvenile rheumatoid arthritis.

B cell lymphoma.

of patients. Fourteen per cent $(24 / 169$; no data $=2)$ of patients showed ocular symptoms at manifestation of disease, consistent with the diagnosis of TINU syndrome. In 22 of 24 patients with ocular symptoms TINU was diagnosed, and vice versa, $58 \%(31 / 53)$ of TINU patients had no ocular symptoms at onset of renal disease.

Polyuria, nocturia or enuresis (12 patients), weight loss (10 patients) and headache (seven patients) were the most frequent additional symptoms given in free-text answers.

\section{Histological findings}

The most frequent histological findings were interstitial infiltration in 95\% (162/170; no data $=1)$ and interstitial oedema in $63 \%(106 / 167$; no data $=4)$ of patients. Interstitial granulomas were reported in $6 \%(11 / 171)$ of patients, among them drug-induced (four patients), idiopathic (four patients) and TINU cases (two patients) and one patient with sarcoidosis.

Interstitial fibrosis and tubular atrophy as markers of chronic renal damage were seen in $38 \%(64 / 170$; no data $=1)$ and $38 \%(65 / 171)$, respectively, whereas glomerulosclerosis was present in only $7 \%(12 / 171)$ of patients. Anonymised copies of original biopsy results were available in seven cases.

\section{Treatment}

\section{Corticosteroids}

Eighty per cent of patients $(137 / 171)$ were treated with corticosteroids (intravenous and/or oral); $20 \%$ (34/171) did not receive any corticosteroids. Forty per cent of patients received a combination of intravenous steroids followed by oral steroids. Details of corticosteroid treatment in the patient group are summarised in table 3.

Ninety-six per cent $(131 / 137)$ of steroid-treated patients received oral corticosteroids. Median duration of oral corticosteroid treatment was 90 days (4-1365). Fortyfour per cent $(60 / 137)$ of steroid-treated patients were

Table 2 Clinical and urinary features at presentation in patients with acute tubulointerstitial nephritis (TIN)

Features

Number of No
patients data

Clinical features

\begin{tabular}{|c|c|c|c|}
\hline Fatigue & $70 \%$ & $119 / 171$ & 0 \\
\hline Vomiting/nausea & $49 \%$ & $83 / 169$ & 2 \\
\hline Fever & $43 \%$ & $73 / 171$ & 0 \\
\hline Flank pain & $33 \%$ & $56 / 168$ & 3 \\
\hline Arterial hypertension & $22 \%$ & $38 / 171$ & 0 \\
\hline Oliguria/anuria & $20 \%$ & $35 / 171$ & 0 \\
\hline Ocular symptoms & $14 \%$ & $24 / 169$ & 2 \\
\hline Joint pain & $14 \%$ & $24 / 169$ & 2 \\
\hline Exanthema & $6 \%$ & $11 / 171$ & 0 \\
\hline \multicolumn{4}{|l|}{ Urinary features } \\
\hline Tubular proteinuria & $72 \%$ & $79 / 109$ & 62 \\
\hline Glucosuria & $56 \%$ & $80 / 143$ & 28 \\
\hline $\begin{array}{l}\text { Glomerular proteinuria, non-nephrotic range }\left(<1000 \mathrm{mg} / \mathrm{m}^{2} \mathrm{BSA} / \text { day in } 24 \text { hours }\right. \\
\text { urine collection or }<2 \mathrm{~g} / \mathrm{g} \text { creatinine in spot urine sample) }\end{array}$ & $53 \%$ & $90 / 171$ & 0 \\
\hline Microscopic haematuria & $39 \%$ & $66 / 170$ & 1 \\
\hline Leukocyturia & $29 \%$ & $49 / 170$ & 1 \\
\hline $\begin{array}{l}\text { Glomerular proteinuria, nephrotic-range }\left(>1000 \mathrm{mg} / \mathrm{m}^{2} \mathrm{BSA} / \text { day in } 24 \text { hours urine }\right. \\
\text { collection or }>2 \mathrm{~g} / \mathrm{g} \text { creatinine in spot urine sample) }\end{array}$ & $11 \%$ & $19 / 171$ & 0 \\
\hline Urinary eosinophilia & $9 \%$ & $7 / 78$ & 93 \\
\hline Macroscopic haematuria & $8 \%$ & $14 / 169$ & 2 \\
\hline
\end{tabular}




\begin{tabular}{|c|c|c|}
\hline $\begin{array}{l}\text { Corticosteroid-treated } \\
\text { patients }\end{array}$ & $\begin{array}{l}\mathrm{n}=137(\stackrel{\wedge}{=} \\
100 \%)\end{array}$ & $\begin{array}{l}\text { Median dosage } \\
\text { and range (in } \mathrm{mg} / \\
\mathrm{kg} / \text { day) }\end{array}$ \\
\hline \multicolumn{3}{|l|}{ Route of administration } \\
\hline $\begin{array}{l}\text { Oral CS, no intravenous } \\
\text { CS }\end{array}$ & $56 \%$ & \\
\hline $\begin{array}{l}\text { Intravenous CS, no oral } \\
\text { CS }\end{array}$ & $4 \%$ & \\
\hline Oral+intravenous CS & $40 \%$ & \\
\hline \multicolumn{3}{|l|}{ Substance } \\
\hline Oral prednisone & $31 \%$ & $1.03(0.40-2.33)$ \\
\hline Oral prednisolone & $56 \%$ & $1.00(0.35-2.00)$ \\
\hline Oral methlyprednisolone & $7 \%$ & $0.97(0.67-4.00)$ \\
\hline Intravenous prednisolone & $7 \%$ & $6.94(0.66-22.73)$ \\
\hline $\begin{array}{l}\text { Intravenous } \\
\text { methylprednisolone }\end{array}$ & $37 \%$ & $10.81(1.63-30.00)$ \\
\hline Unknown oral CS & $1 \%$ & - \\
\hline
\end{tabular}

CS, corticosteroids; IV, intravenous.

treated with intravenous corticosteroids with a median treatment duration (range) of 3 days (1-6).

Eighteen per cent $(31 / 171)$ of all patients included in the study were treated with non-corticosteroid immunosuppressive drugs. Of these, all but one patient (patient with TIN as a complication of autoimmune polyendocrinopathy-candidiasis-ectodermal dystrophy (APECED) type 1) were additionally treated with corticosteroids (oral and/or intravenous). MMF was the most frequently used non-corticosteroid immunosuppressant in $12 \%(21 / 171)$ of all cases. Details of immunosuppressive treatment are given in table 4 .

\section{Renal function and residual damage}

Serum creatinine levels were collected at time of renal biopsy, 2 weeks and 3-6 months later. Renal function parameters at biopsy were available for all 171 patients, serum creatinine levels 2 weeks and 3-6 months after renal biopsy were given for 168 and 164 patients, respectively.

For all patients, median eGFR rose significantly from 31 (3-182) $\mathrm{mL} / \mathrm{min} / 1.73 \mathrm{~m}^{2}$ at renal biopsy to 86 (7-169) $\mathrm{mL} / \mathrm{min} / 1.73 \mathrm{~m}^{2} 3-6$ months after renal biopsy $(p<0.001)$. After 2 weeks, renal function had already significantly improved with a median eGFR of $67 \mathrm{~mL} /$ $\min / 1.73 \mathrm{~m}^{2}(5-167) \quad(\mathrm{p}<0.001)$ (see figure 3A). Significant improvement in renal function was detectable in every aetiological subgroup 2 weeks and 3-6 months after renal biopsy (see figure $3 \mathrm{~B}$ and $\mathrm{C}$ ). The median rise in eGFR was $22-96 \mathrm{~mL} / \mathrm{min} / 1.73 \mathrm{~m}^{2}$ in drug-induced TIN, $36-85 \mathrm{~mL} / \mathrm{min} / 1.73 \mathrm{~m}^{2}$ in TINU syndrome, $36-81 \mathrm{~mL} /$ $\min / 1.73 \mathrm{~m}^{2}$ in idiopathic TIN, $35-72 \mathrm{~mL} / \mathrm{min} / 1.73 \mathrm{~m}^{2}$ in TIN associated with systemic diseases and $28-98 \mathrm{~mL} /$ $\min / 1.73 \mathrm{~m}^{2}$ in TIN associated with infections.
Table 4 Immunosuppressants in 31 patients with acute tubulointerstitial nephritis (TIN)

\begin{tabular}{|c|c|c|}
\hline Immunosuppressant & $\begin{array}{l}\text { Indication (number of } \\
\text { treated patients) }\end{array}$ & $\begin{array}{l}\text { Total } \\
\text { number } \\
\text { of treated } \\
\text { patients }\end{array}$ \\
\hline Mycophenolate mofetil & $\begin{array}{l}\text { Drug-induced TIN (3), } \\
\text { TINU (11), idiopathic TIN } \\
\text { (5), systemic disease (2) }\end{array}$ & 21 \\
\hline Azathioprine & $\begin{array}{l}\text { Drug-induced TIN (1), } \\
\text { TINU (1), idiopathic TIN } \\
\text { (3) }\end{array}$ & 5 \\
\hline Cyclosporine & $\begin{array}{l}\text { TINU (1), idiopathic TIN } \\
\text { (2) }\end{array}$ & 3 \\
\hline Methotrexate & $\begin{array}{l}\text { TINU (2), systemic } \\
\text { disease (1) }\end{array}$ & 3 \\
\hline Cyclophosphamide & $\begin{array}{l}\text { Idiopathic TIN (1), } \\
\text { systemic disease (1) }\end{array}$ & 2 \\
\hline Rituximab & Systemic disesase & 1 \\
\hline Eculizumab & Systemic disesase & 1 \\
\hline Hydroxychloroquine & Systemic disesase & 1 \\
\hline
\end{tabular}

More than one medication was administered in several cases. TINU, tubulointerstitial nephritis with uveitis.

eGFR was normalised $\left(>90 \mathrm{~mL} / \mathrm{min} / 1.73 \mathrm{~m}^{2}\right)$ in $41 \%$ $(67 / 164 ;$ no data $=7)$ after $3-6$ months, $59 \%(97 / 164)$ had an impaired eGFR $\left(<90 \mathrm{~mL} / \mathrm{min} / 1.73 \mathrm{~m}^{2}\right)$. Most patients $(47 \%=77 / 164)$ showed a mild reduction in glomerular filtration rate $\left(60-89 \mathrm{~mL} / \mathrm{min} / 1.73 \mathrm{~m}^{2}\right)$, while a mild to moderate impairment $\left(30-59 \mathrm{~mL} / \mathrm{min} / 1.73 \mathrm{~m}^{2}\right)$ was present in 9\% (14/164). Only 3\% (6/164) had eGFR $<30 \mathrm{~mL} / \mathrm{min} / 1.73 \mathrm{~m}^{2}$ (see table 5 ).

Median eGFR after 3-6 months was $85(8-168) \mathrm{mL} /$ $\min / 1.73 \mathrm{~m}^{2}$ in the steroid group and $91(7-135) \mathrm{mL} /$ $\min / 1.73 \mathrm{~m}^{2}$ in the non-steroid group $(\mathrm{p}=0.10)$. Before initiation of treatment, steroid-treated patients had a significantly lower eGFR than patients who were not treated with steroids $\left(30 \mathrm{~mL} / \mathrm{min} / 1.73 \mathrm{~m}^{2}\right.$ compared with $\left.38 \mathrm{~mL} / \mathrm{min} / 1.73 \mathrm{~m}^{2}\right)(\mathrm{p}=0.03)$ (see table 6$)$.

Seven per cent $(12 / 171)$ needed renal replacement therapy either as haemodialysis $(7 / 171)$ or peritoneal dialysis $(5 / 171)$. Median duration (range) of renal replacement therapy was 6.5 (2-180) days. Seven (12/164; no data $=7$ ) of patients had glomerular proteinuria 3-6 months after renal biopsy and in 19\% (32/164) urinalysis showed persistent tubular proteinuria. Mixed proteinuria (glomerular and tubular) was detected in 9\% (14/164). The majority of patients $(65 \%=106 / 164)$ had no residual proteinuria. The prevalence of proteinuria (glomerular and/or tubular) did not differ between steroid-treated and untreated patients $(\mathrm{p}=0.50)$.

Arterial hypertension treated with medication was present in $19 \%$ (32/171), $17 \%$ (28/171) needed one or two antihypertensive drugs, $2 \%(4 / 171)$ were treated with three or more antihypertensives. Most patients 

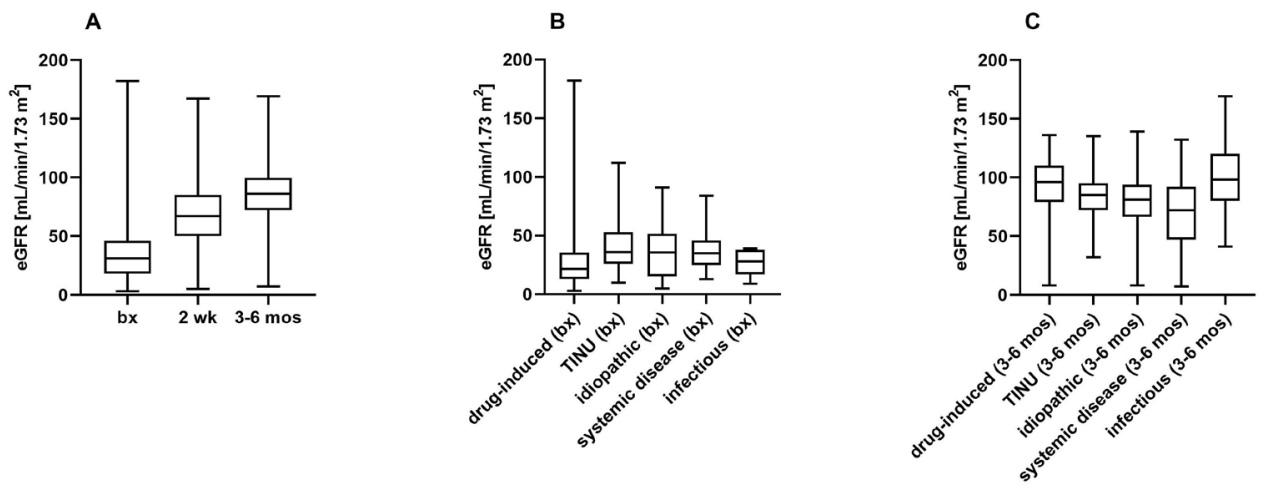

Figure 3 (A) Significant improvement of estimated glomerular filtration rate (eGFR) 2 weeks and 3-6 months after renal biopsy in patients with acute tubulointerstitial nephritis (TIN). (B and C) Significant improvement of GFR in all etiological subgroups with acute TIN. TINU, tubulointerstitial nephritis with uveitis.

$(81 \%=139 / 171)$ did not need antihypertensive treatment. Significantly more steroid-treated patients than patients without steroid treatment needed antihypertensive treatment $3-6$ months later $(22 \%$ vs $6 \%, \mathrm{p}=0.03)$.

\section{DISCUSSION}

The results of this survey shed some light on cause, clinical management and outcome of TIN in paediatric patients. To the best of our knowledge, our findings are from the largest paediatric TIN cohort to date.

The clinical presentation of TIN was unspecific with fatigue, vomiting or nausea and fever being the most frequent features. Only one patient of $171(0.6 \%)$ showed the 'classic' triad of fever, arthralgia and skin rash or exanthema that dominated the clinical picture in early reports of mainly drug-induced cases. Actually, this symptom triad occurred in $5 \%-10 \%$ of patients in earlier reports. ${ }^{9} 18$

Drug-induced TIN is the underlying cause in $60 \%-70 \%$ of cases in adults. ${ }^{6} 18$ In our cohort, drugs were responsible for only $30 \%$ of TIN cases. The fact that only biopsyproven cases were included in our analysis might be responsible for a lower percentage of drug-induced cases since in clinical practice patients with typical clinical hallmarks of drug-induced TIN and mild to moderate renal failure do not always undergo renal biopsy. NSAIDs and antimicrobials are the most common culprits in druginduced TIN. ${ }^{6}{ }^{19}$ Whether NSAIDs or antimicrobials are the leading class of drugs in the aetiology of TIN, however, is a matter of debate..$^{1112021}$ In our paediatric cohort, NSAIDs were identified as the leading cause in $48 \%$ of

Table 5 Development of estimated glomerular filtration rate (eGFR) $\left.\left(\mathrm{mL} / \mathrm{min} / 1.73 \mathrm{~m}^{2}\right)\right] 2$ weeks and 3-6 months after diagnosis of acute tubulointerstitial nephritis (TIN)

\begin{tabular}{llcllrr}
\hline & $\begin{array}{l}\text { Number } \\
\text { of } \\
\text { patients }\end{array}$ & $\geq \mathbf{9 0}$ & $\mathbf{6 0 - 8 9}$ & $\mathbf{3 0 - 5 9}$ & $\mathbf{1 5 - 2 9}$ & $<\mathbf{1 5}$ \\
\cline { 2 - 7 } & 171 & $3 \%$ & $11 \%$ & $40 \%$ & $27 \%$ & $19 \%$ \\
\hline Biopsy & 171 & $\left.\mathbf{m L} / \mathbf{m i n} / \mathbf{1 . 7 3} \mathbf{~ m}^{\mathbf{2}}\right)$ & \\
\hline 2 weeks & 168 & $20 \%$ & $42 \%$ & $34 \%$ & $2 \%$ & $2 \%$ \\
\hline $3-6$ months & 164 & $41 \%$ & $47 \%$ & $9 \%$ & $1 \%$ & $2 \%$ \\
\hline
\end{tabular}

patients with drug-induced TIN, and another 10\% had a history of NSAIDs plus antimicrobial intake. Coadministration of two or more drugs can make it difficult to identify the culpable agent, but NSAIDs clearly represent the main cause for drug-induced TIN in our study, followed by antibiotics (21\% of drug-induced cases). Although proton-pump inhibitors (PPIs) are a widely prescribed class of drugs and have been considered a relevant cause of acute TIN since the first published report of PPIinduced TIN in $1992,{ }^{22-25}$ no case of PPI-induced TIN was found in our cohort.

Remarkably, three patients had a history of herbal medicine intake. Aristolochic acid and other plant alkaloids have been identified as nephrotoxic ingredients in Chinese herbal medicine, and interstitial nephritis is one possible manifestation of its nephrotoxic capacity. ${ }^{26}{ }^{27}$ Furthermore, interstitial nephritis was triggered by bee stings in two patients. Acute kidney injury due to immunemediated acute interstitial nephritis has been reported as a rare complication of Hymenoptera stings (bees and wasps) in a number of case reports or case series. ${ }^{28-30}$ Another patient developed acute TIN after smoking a potentially nephrotoxic substance. A number of legal and illegal drugs should be taken into consideration as possible triggers of TIN, particularly in adolescents. For example, synthetic cannabinoids have become popular recreational drugs with $\Delta 9$-tetrahydrocannabinol-like effects that are solubilised, sprayed onto herbal mixtures and usually smoked. Renal manifestations of synthetic

Table 6 Development of estimated glomerular filtration rate (eGFR) in patients without corticosteroid treatment versus patients with corticosteroid treatment

\begin{tabular}{llll}
\hline & $\begin{array}{l}\text { Corticosteroid } \\
\text { treatment }(\mathbf{n = 1 3 7})\end{array}$ & $\begin{array}{l}\text { No corticosteroid } \\
\text { treatment }(\mathbf{n}=\mathbf{3 4})\end{array}$ & P value \\
\hline Biopsy & $30(3-182)$ & $38(9-112)$ & 0.03 \\
2 weeks & $67(5-167)$ & $67(25-132)$ & 0.86 \\
3-6 months & $85(8-169)$ & $91(7-135)$ & 0.10 \\
\hline
\end{tabular}

Values for eGFR $\left(\mathrm{mL} / \mathrm{min} / 1.73 \mathrm{~m}^{2}\right)$ are given as median with range. 
cannabinoid use are acute tubular necrosis and acute interstitial nephritis. ${ }^{31}$ Our results show that a variety of drugs, medications and toxic agents are involved in the pathogenesis of acute interstitial nephritis and should be considered as a potential aspect of the patient's medical history.

TIN was associated with systemic diseases in $7 \%$ of patients. In adults, systemic diseases underlie 10\%-15\% of cases. ${ }^{19}$ Sjögren's syndrome and sarcoidosis are well described autoimmune disorders with TIN as typical renal manifestation. Interstitial nephritis is the prevalent renal finding in Sjögren's syndrome; $98 \%$ of patients with renal involvement show TIN in renal biopsy. ${ }^{32}$ TIN associated with APECED type $1,{ }^{33}{ }^{34}$ microscopic polyangiitis, ${ }^{35}$ familial Mediterranean fever, ${ }^{36}{ }^{37}$ rheumatoid arthritis ${ }^{38}$ and malignant infiltration ${ }^{39}$ has been described in the literature. The case of a 17-year-old girl with atypical haemolytic uraemic syndrome and acute TIN included in our analysis has also been described by Basak et al. ${ }^{40}$

Infectious causes were found in $4 \%$ (in adults $\left.5 \%-10 \%{ }^{19}\right)$. Only viral and no bacterial, fungal or parasitic pathogens were identified. Adenovirus, BK polyoma virus (both predominantly in renal transplant patients) and hepatitis $\mathrm{C}$ have been described as infectious causes of TIN. ${ }^{41-43}$ Three patients had symptoms of upper respiratory tract infection without pathogen identification, and rhinovirus was identified in another patient. It remains unclear if a bacterial or viral pathogen was the unequivocal cause of TIN in these cases or if other underlying factors played a role in the pathogenesis (eg, intake of NSAIDs or antibiotics to treat respiratory symptoms). It has to be noted that all diagnoses were established by the participating physicians based on biopsy results and clinical findings.

TINU is thought to be a rare condition with an incidence of uveitis among TIN patients of less than $10 \% .^{18}$ Jahnukainen et $a l^{44}$ reported that uveitis was diagnosed in $46 \%$ in a case series of 26 children with 'idiopathic TIN', supporting the assumption that the prevalence of uveitis among TIN patients is higher than previously assumed. In our study, $58 \%$ of TINU patients had no ocular symptoms at onset of renal disease. This is in line with previous reports that uveitis may evolve up to 14 months after the onset of $\operatorname{TIN}^{45} 46$ and that a high percentage of TINU patients are ophthalmologically asymptomatic at the onset of renal symptoms. ${ }^{44}$ Thorough ophthalmological examinations over months after the onset of TIN are necessary even in patients without ocular symptoms. ${ }^{446}$ Our results support the rationale for this recommendation.

In our study, the overall renal outcome 3-6 months after diagnosis of TIN was favourable with a rise in median eGFR from 31 to $86 \mathrm{~mL} / \mathrm{min} / 1.73 \mathrm{~m}^{2}$. Only $2 \%$ (two patients with idiopathic TIN, one patient with druginduced TIN and another patient with systemic disease) had eGFR $<15 \mathrm{~mL} / \mathrm{min} / 1.73 \mathrm{~m}^{2}$ (CKD 5 ).

The role of corticosteroids in the treatment of TIN has remained controversial. Available studies in adults are retrospective and not controlled and deliver partially contradictory results. ${ }^{11-15}$ A prospective paediatric study with 17 patients showed that prednisone speeds up renal recovery, but there was no significant difference in renal function between prednisone and control patients after 6 months' follow-up. ${ }^{16}$

In our study, renal function improved significantly after 2 weeks and showed further significant improvement 3-6 months after kidney biopsy. This development of eGFR was found in all aetiological subgroups. Corticosteroid treatment of TIN seems well established among paediatric nephrologists, since $80 \%$ of included patients received steroids. Whereas patients who were not treated with steroids had a significantly better median eGFR than patients who underwent steroid therapy at time of renal biopsy, there was no significant difference in eGFR 2 weeks and 3-6 months later and the rate of glomerular and/or tubular proteinuria 3-6 months later. However, we were not able to evaluate the efficacy of corticosteroid treatment of acute TIN since the number of patients was not equally distributed between the steroid-treated and untreated group ( $80 \%$ receiving steroid treatment) and long-term effects of corticosteroid treatment were not monitored. MMF is an additional treatment option in paediatric TIN patients with different etiological backgrounds but was exclusively used in combination with corticosteroids (the exception being one patient with APECED type 1 syndrome, treated with MMF and rituximab). MMF has been described as a successful therapeutic option for steroid-resistant or intolerant patients. ${ }^{47}$

\section{Strengths and limitations of our study}

Our results are based on retrospective data collected in an online survey. This method of data collection requires concise and comprehensive questions but at the same time needs to be feasible and low threshold. We were not able to check the data for correctness but relied on the clinical data given by the participants.

Our follow-up period of 3-6 months is relatively short. In a larger and, at best, prospective study on paediatric TIN, we propose a follow-up period of at least 1 year. Biopsy results were not available as original copies apart from a few cases. Thus, we were not able to grade the degree of histological changes (eg, interstitial fibrosis). Ideally, all original biopsy samples should be re-evaluated by one pathologist. As many TIN patients with mild or moderate renal failure do not undergo kidney biopsy in all centres, severe cases were presumably over-represented in our study population.

The main strength of our study is the high number of patients and participating centres. It is the largest collection of children with TIN until now.

\section{Conclusion}

Data from this large cohort suggest an overall positive outcome of biopsy-proven acute TIN in paediatric patients. Eighty-eight per cent of patients showed no or mild impairment of renal function 3-6 months after TIN was diagnosed. Prospective randomised controlled trials 
are required to determine the efficacy of corticosteroids in the management of acute TIN in paediatric patients.

\section{Author affiliations}

${ }^{1}$ Department of Pediatric Nephrology, MHH, Hannover, Germany

${ }^{2}$ Department of Pediatric Nephrology, Veltischev Research and Clinical Institute for Pediatrics of the Pirogov Russian National Research Medical University, Moskva, Russian Federation

${ }^{3}$ Department of Pediatric Nephrology, Temple Street Children's University Hospital, Dublin, Ireland

${ }^{4}$ Department of Pediatric Nephrology, Cipto Mangunkusumo Hospital, Faculty of Medicine, University of Indonesia, Central Jakarta, Indonesia

${ }^{5}$ Department of Pediatric Nephrology, Meyer Children's Hospital, Florence, Italy ${ }^{6}$ Department of Pediatric Nephrology, Bambino Gesù Children's Hospital, Roma, Italy ${ }^{7}$ Department of Pediatric Nephrology, Montpellier University, Arnaud de Villeneuve Hospital, Montpellier, France

${ }^{8}$ Department of Pediatric Nephrology, Dona Estefânia Hospital, Lisboa, Portugal ${ }^{9}$ Department of Pediatric Nephrology, Faculty of Medicine, Marmara University, Istanbul, Turkey

${ }^{10}$ Department of Pediatric Nephrology, Faculty of Medicine, Hacettepe University, Ankara, Turkey

${ }^{11} \mathrm{KfH}$ Centre of Pediatric Nephrology, Clementine Kinderhospital, Frankfurt am Main, Germany

${ }^{12}$ Department of Pediatric Nephrology and Transplantation, New Children's Hospital and Helsinki University Hospital, Helsinki, Finland

${ }^{13}$ Department of Pediatric Nephrology, Nationwide Children's Hospital, Columbus, Ohio, USA

${ }^{14}$ Department of Pediatric Nephrology, Aarhus University Hospital, Aarhus, Denmark

${ }^{15}$ Department of Pediatric Nephrology, Connecticut Children's Medical Center,

Hartford, Connecticut, USA

${ }^{16}$ Department of Pediatric Nephrology, Fondazione IRCCS Ca' Granda Ospedale Maggiore Policlinico, Milan, Italy

${ }^{17}$ Department of Pediatric Nephrology, Azienda Ospedaliero-Universitaria di Bologna, Ospedale S. Orsola-Malpighi, Bologna, Italy

${ }^{18}$ Department of Pediatric Nephrology, Karolinska University Hospital, Stockholm, Sweden

${ }^{19}$ Department of Pediatric Nephrology, University Children's Hospital, Ljubljana, Slovenia

${ }^{20}$ Department of Pediatric Nephrology, Faculty of Medicine, Istanbul UniversityCerrahpasa, Istanbul, Turkey

${ }^{21}$ Department of Pediatric Nephrology, Dr Behcet Uz Children Hospital, Izmir, Turkey

${ }^{22}$ Department of Pediatric Nephrology, Faculty of Medicine, Ege University, Izmir, Turkey

${ }^{23}$ Department of Pediatric Nephrology, University Hospital of Padova, Padova, Italy

${ }^{24}$ Department of Pediatric Nephrology, Stony Brook Children's Hospital, Stony Brook, New York, USA

${ }^{25}$ Department of Pediatric Nephrology, Faculty of Medicine, Erciyes University, Kayseri, Turkey

${ }^{26}$ Department of Pediatric Nephrology, 2nf Faculty of Medicine, University Hospital Motol, Charles University, Praha, Czech Republic

${ }^{27}$ Department of Pediatrics II, University Hospital Essen, Essen, Germany

Twitter Francesca Becherucci @FrancescaBeche2 and Seha Saygili @sehasaygili

Acknowledgements We would like to thank the German Society of Pediatric Nephrology (GPN), the European Society of Pediatric Nephrology (ESPN), the European Network of Rare Kidney Diseases (ERKnet) and the Pediatric Nephrology Research Consortium (PNRC) for the support of this project.

Collaborators The international TIN study group consists of the authors listed, as well as of: Olivia Boyer (Hôpital Necker-Enfants malades, MARHEA, Institut Imagine, Université de Paris, Paris, France); Kathrin Buder (Pediatric Department, University Hospital Carl Gustav Carus, Technical University Dresden, Germany); İpek Kaplan Bulut (Ege University Faculty of Medicine, Izmir, Turkey); Elisabeth AM Cornelissen (Radboud University Medical Center, Nijmegen, Netherlands); Maria del Mar Espino Hernández (Hospital Universitario 12 de Octubre, Madrid, Spain); Nakysa Hooman (Ali-Asghar Clinical Research Development Center, Iran University of Medical Sciences, Tehran, Iran); Markus Kemper (Asklepios Medical School, Hamburg, Germany); Julie Maquet (CHC Liège, Belgium); Fernando Santos (Pediatric Nephrology, Hospital Universitario Central de Asturias \& University of Oviedo, Spain); Ulrike Walden (Universitätsklinikum Kinderklinik Augsburg, Germany).

Contributors SW-S collected data, did the statistical analyses and wrote the first draft of the manuscript. SW-S, LP, MA, AA, FB, CGA, FE, MF, TF, IG, BG, MH, TJ, MK, KK, SM, AM, FM, BN-F, MR, RR, SS, ES, ST, RT, EV, RW, SY and JZ provided patient data. LP designed the project and revised the manuscript. All authors accepted the final version of the manuscript.

Funding The authors have not declared a specific grant for this research from any funding agency in the public, commercial or not-for-profit sectors.

Competing interests None declared.

Patient consent for publication Not required.

Ethics approval The study received approval from the ethics committee of Hannover Medical School Nr. 3210-2016.

Provenance and peer review Not commissioned; externally peer reviewed.

Data availability statement Data are available on reasonable request. The data underlying this article will be shared on reasonable request to the corresponding author.

Supplemental material This content has been supplied by the author(s). It has not been vetted by BMJ Publishing Group Limited (BMJ) and may not have been peer-reviewed. Any opinions or recommendations discussed are solely those of the author(s) and are not endorsed by BMJ. BMJ disclaims all liability and responsibility arising from any reliance placed on the content. Where the content includes any translated material, BMJ does not warrant the accuracy and reliability of the translations (including but not limited to local regulations, clinical guidelines, terminology, drug names and drug dosages), and is not responsible for any error and/or omissions arising from translation and adaptation or otherwise.

Open access This is an open access article distributed in accordance with the Creative Commons Attribution Non Commercial (CC BY-NC 4.0) license, which permits others to distribute, remix, adapt, build upon this work non-commercially, and license their derivative works on different terms, provided the original work is properly cited, appropriate credit is given, any changes made indicated, and the use is non-commercial. See: http://creativecommons.org/licenses/by-nc/4.0/.

ORCID iDs

Marc Fila http://orcid.org/0000-0001-8857-7100

Lars Pape http://orcid.org/0000-0002-3635-6418

\section{REFERENCES}

1 Clarkson MR, Giblin L, O'Connell FP, et al. Acute interstitial nephritis: clinical features and response to corticosteroid therapy. Nephrol Dial Transplant 2004;19:2778-83.

2 Goicoechea M, Rivera F, López-Gómez JM. Spanish registry of glomerulonephritis. increased prevalence of acute tubulointerstitial nephritis. Nephrol Dial Transplant 2013;28:112-5.

3 Raghavan R, Eknoyan G. Acute interstitial nephritis - a reappraisal and update. Clin Nephrol 2014;82:149-62.

4 Verghese PS, Luckritz KE, Eddy AA. Interstitial nephritis in children. In: Geary DF, Schaefer F, eds. Pediatric kidney disease. Berlin Heidelberg, Germany: Springer-Verlag, 2016: 1013-36.

5 Hodgkins KS, Schnaper HW. Tubulointerstitial injury and the progression of chronic kidney disease. Pediatr Nephrol 2012;27:901-9.

6 Perazella MA, Markowitz GS. Drug-induced acute interstitial nephritis. Nat Rev Nephrol 2010;6:461-70.

7 Takemura T, Okada M, Hino S, et al. Course and outcome of tubulointerstitial nephritis and uveitis syndrome. Am J Kidney Dis 1999;34:1016-21.

8 Vohra S, Eddy A, Levin AV, et al. Tubulointerstitial nephritis and uveitis in children and adolescents. Four new cases and a review of the literature. Pediatr Nephrol 1999;13:426-32.

9 Rossert J. Drug-induced acute interstitial nephritis. Kidney Int 2001;60:804-17.

10 Joyce E, Glasner P, Ranganathan S, et al. Tubulointerstitial nephritis: diagnosis, treatment, and monitoring. Pediatr Nephrol 2017;32:577-87.

11 González E, Gutiérrez E, Galeano C, et al. Early steroid treatment improves the recovery of renal function in patients with drug-induced acute interstitial nephritis. Kidney Int 2008;73:940-6.

12 Buysen JG, Houthoff HJ, Krediet RT, et al. Acute interstitial nephritis: a clinical and morphological study in 27 patients. Nephrol Dial Transplant 1990;5:94-9. 
13 Galpin JE, Shinaberger JH, Stanley TM, et al. Acute interstitial nephritis due to methicillin. Am J Med 1978;65:756-65.

14 Pusey CD, Saltissi D, Bloodworth L, et al. Drug associated acute interstitial nephritis: clinical and pathological features and the response to high dose steroid therapy. Q J Med 1983;52:194-211.

15 Bhaumik SK, Kher V, Arora P, et al. Evaluation of clinical and histological prognostic markers in drug-induced acute interstitial nephritis. Ren Fail 1996;18:97-104.

16 Jahnukainen T, Saarela V, Arikoski P, et al. Prednisone in the treatment of tubulointerstitial nephritis in children. Pediatr Nephrol 2013;28:1253-60.

17 Schwartz GJ, Muñoz A, Schneider MF, et al. New equations to estimate GFR in children with CKD. J Am Soc Nephrol 2009;20:629-37.

18 Baker RJ, Pusey CD. The changing profile of acute tubulointerstitial nephritis. Nephrol Dial Transplant 2004;19:8-11.

19 Praga M, González E. Acute interstitial nephritis. Kidney Int 2010;77:956-61.

20 Schwarz A, Krause PH, Kunzendorf U, et al. The outcome of acute interstitial nephritis: risk factors for the transition from acute to chronic interstitial nephritis. Clin Nephrol 2000;54:179-90.

21 Muriithi AK, Leung N, Valeri AM, et al. Biopsy-proven acute interstitial nephritis, 1993-2011: a case series. Am J Kidney Dis 2014;64:558-66.

22 Ruffenach SJ, Siskind MS, Lien YH. Acute interstitial nephritis due to omeprazole. Am J Med 1992;93:472-3.

23 Torpey N, Barker T, Ross C. Drug-induced tubulo-interstitial nephritis secondary to proton pump inhibitors: experience from a single UK renal unit. Nephrol Dial Transplant 2004;19:1441-6.

24 Geevasinga N, Coleman PL, Webster AC, et al. Proton pump inhibitors and acute interstitial nephritis. Clin Gastroenterol Hepatol 2006;4:597-604.

25 Simpson IJ, Marshall MR, Pilmore H, et al. Proton pump inhibitors and acute interstitial nephritis: report and analysis of 15 cases. Nephrology 2006;11:381-5.

26 Yang B, Xie Y, Guo M, et al. Nephrotoxicity and Chinese herbal medicine. Clin J Am Soc Nephrol 2018;13:1605-11.

27 Petejova N, Martinek A, Zadrazil J, et al. Acute toxic kidney injury. Ren Fail 2019;41:576-94.

28 Nandi M, Sarkar S. Acute kidney injury following multiple wasp stings. Pediatr Nephrol 2012;27:2315-7.

29 Bhatta N, Singh R, Sharma S, et al. Acute renal failure following multiple wasp stings. Pediatr Nephrol 2005;20:1809-10.

30 Ambarsari CG, Sindih RM, Saraswati M, et al. Delayed admission and management of pediatric acute kidney injury and multiple organ dysfunction syndrome in children with multiple wasp stings: a case series. Case Rep Nephrol Dial 2019;9:137-48.
31 Pendergraft WF, Herlitz LC, Thornley-Brown D, et al. Nephrotoxic effects of common and emerging drugs of abuse. Clin J Am Soc Nephrol 2014;9:1996-2005.

32 Jasiek M, Karras A, Le Guern V, et al. A multicentre study of 95 biopsy-proven cases of renal disease in primary Sjögren's syndrome. Rheumatology 2017;56:362-70.

33 Gwertzman R, Corey H, Roberti I. Autoimmune polyglandular syndrome type I can have significant kidney disease in children including recurrence in renal allograft - a report of two cases. Clin Nephrol 2016;85:358-62.

34 Kluger N, Kataja J, Aho H, et al. Kidney involvement in autoimmune polyendocrinopathy-candidiasis-ectodermal dystrophy in a Finnish cohort. Nephrol Dial Transplant 2014;29:1750-7.

35 Wen YK, Chen ML. Microscopic polyangiitis atypically presenting with tubulointerstitial nephritis. Clin Nephrol 2006;65:356-60.

36 Kukuy O, Livneh A, Ben-David A, et al. Familial Mediterranean fever (FMF) with proteinuria: clinical features, histology, predictors, and prognosis in a cohort of 25 patients. J Rheumatol 2013;40:2083-7.

37 Sarı İsmail, Birlik M, Kasifoğlu T. Familial Mediterranean fever: an updated review. Eur J Rheumatol 2014;1:21-33.

38 Makino $\mathrm{H}$, Yoshinaga $\mathrm{Y}$, Yamasaki $\mathrm{Y}$, et al. Renal involvement in rheumatoid arthritis: analysis of renal biopsy specimens from 100 patients. Mod Rheumatol 2002;12:148-54.

39 Corlu L, Rioux-Leclercq N, Ganard M, et al. Renal dysfunction in patients with direct infiltration by B-cell lymphoma. Kidney Int Rep 2019;4:688-97.

40 Basak R, Wang X, Keane C, et al. Atypical presentation of atypical haemolytic uraemic syndrome. BMJ Case Rep 2018;31:bcr2017222560.

41 Veer M, Abdulmassih R, Como J, et al. Adenoviral nephritis in a renal transplant recipient: case report and literature review. Transpl Infect Dis 2017;19:e12716. doi:10.1111/tid.12716

42 Menter T, Mayr M, Schaub S, et al. Pathology of resolving polyomavirus-associated nephropathy. Am J Transplant 2013;13:1474-83.

43 Sumida K, Ubara Y, Hoshino J, et al. Hepatitis C virus-related kidney disease: various histological patterns. Clin Nephrol 2010;74:446-56.

44 Jahnukainen T, Ala-Houhala M, Karikoski R, et al. Clinical outcome and occurrence of uveitis in children with idiopathic tubulointerstitial nephritis. Pediatr Nephrol 2011;26:291-9.

45 Mandeville JT, Levinson RD, Holland GN. The tubulointerstitial nephritis and uveitis syndrome. Surv Ophthalmol 2001:46:195-208.

46 Mackensen F, Billing $\mathrm{H}$. Tubulointerstitial nephritis and uveitis syndrome. Curr Opin Ophthalmol 2009;20:525-31.

47 Preddie DC, Markowitz GS, Radhakrishnan J, et al. Mycophenolate mofetil for the treatment of interstitial nephritis. Clin J Am Soc Nephrol 2006;1:718-22. 